\title{
Caenorhabditis elegans LET-502 is related to Rho-binding kinases and human myotonic dystrophy kinase and interacts genetically with a homolog of the regulatory subunit of smooth muscle myosin phosphatase to affect cell shape
}

\author{
Andreas Wissmann, ${ }^{1}$ Julia Ingles, James D. McGhee, and Paul E. Mains \\ University of Calgary, Department of Medical Biochemistry, Calgary Alberta T2N 4N1, Canada
}

We have identified two genes associated with the hypodermal cell shape changes that occur during elongation of the Caenorhabditis elegans embryo. The first gene, called let-502, encodes a protein with high similarity to Rho-binding Ser/Thr kinases and to human myotonic dystrophy kinase (DM-kinase). Strong mutations in let-502 block embryonic elongation, and let-502 reporter constructs are expressed in hypodermal cells at the elongation stage of development. The second gene, mel-11, was identified by mutations that act as extragenic suppressors of let-502. mel-11 encodes a protein similar to the 110- to 133-kD regulatory subunits of vertebrate smooth muscle myosin-associated phosphatase (PP-1M). We suggest that the LET-502 kinase and the MEL-11 phosphatase subunit act in a pathway linking a signal generated by the small GTP-binding protein Rho to a myosin-based hypodermal contractile system that drives embryonic elongation. LET-502 may directly regulate the activity of the MEL-11 containing phosphatase complex and the similarity between LET-502 and DM-kinase suggests a similar function for DM-kinase.

[Key Words: C. elegans morphogenesis; cell shape; signal transduction; Rho; smooth muscle; myotonic dystrophy]

Received September 9, 1996; revised version accepted December 30, 1996.

Many morphogenetic events during animal development involve complex structural rearrangements of epithelial sheets caused by changes in cell shape (for review, see Fristrom 1988). A dramatic example of such a morphogenetic process occurs midway through Caenorhabditis elegans embryogenesis, when the embryo transforms itself from a ball of cells into an elongated vermiform larva. This elongation depends on the presence of hypodermal cells (Sulston et al. 1983), requires microfilaments (Priess and Hirsh 1986), and is accompanied by large shape changes in the hypodermal cells, all suggesting that it is these shape changes that cause the asymmetric squeezing of the embryo. Here we describe the involvement and genetic interaction of two $C$. elegans proteins in a pathway that could drive these changes in cell shape.

An actin-myosin based contractile system most likely drives the cell shape changes involved in epithelial mor-

${ }^{1}$ Corresponding author.

E-MAIL wissmann@acs.ucalgary.ca; FAX (403) 270-0737. phogenesis. Myosins act as molecular motors in both muscle and nonmuscle cells (Sellers 1991; Tan et al. 1992). In some cell types, conventional myosin II (from here on referred to simply as myosin) has been shown to colocalize with microfilaments (Young et al. 1993). Morphological defects are associated with myosin deficient Dictyostelium cells (Manstein et al. 1989; Springer et al. 1994) and Drosophila leg morphogenesis requires both zipper (nonmuscle myosin heavy chain) and spaghettisquash (nonmuscle myosin regulatory light chain) (for review, see von Kalm et al. 1995).

The biochemical regulation of cell shape changes has been studied intensively in smooth muscle contraction (for review, see Allen and Walsh 1994; Somlyo and Somlyo 1994). Ser ${ }^{19}$ of the myosin regulatory light chain is phosphorylated by myosin light chain kinase (MLCK). This phosphorylation markedly increases the actin-activated myosin Mg-ATPase activity, leading to muscle contraction. Dephosphorylation of $\mathrm{Ser}^{19}$ by a myosin phosphatase complex reverses this effect. Although intracellular $\mathrm{Ca}^{2+}$ levels are the main regulator of MLCK 
activity, other mechanisms can alter the state of Ser ${ }^{19}$ phosphorylation levels while $\mathrm{Ca}^{2+}$ levels remain constant. In particular, it has been suggested that signals deriving from the Rho family of small GTP-binding proteins lead to inhibition of myosin phosphatase activity, thus altering Ser $^{19}$ phosphorylation levels (Fujiwara et al. 1989; Kitazawa et al. 1989, 1991; Kubota et al. 1992; Noda et al. 1995; Gong et al. 1996). Kimura et al. (1996) have shown recently that a Rho-binding Ser/Thr kinase (Rho-kinase) can phosphorylate and thereby inhibit the activity of a myosin phosphatase in vitro.

Here we describe evidence for possible intermediates between the small GTP-binding protein Rho and the Ser phosphorylation levels of myosin regulatory light chains that could control embryonic elongation in C. elegans. The C. elegans gene let-502 encodes a Ser/Thr kinase with significant similarity to a group of recently identified Rho-binding kinases as well as to human myotonic dystrophy kinase (DM-kinase). A second gene, me1-11, identified as an extragenic suppressor of let-502 mutations, shows structural and sequence elements characteristic of smooth muscle myosin phosphatase regulatory subunits. The genetic interaction between let-502 and mel-11 suggests a model for cell shape regulation and predicts a possible substrate for DM-kinase.

\section{Results}

Isolation of elongation-defective $\mathrm{C}$. elegans mutants

The ca201 mutation was identified in a screen for zygotic lethal mutations that affect $C$. elegans embryonic morphogenesis. Homozygous ca201 embryos arrest during early elongation (1.5-fold stage) with a homogeneous and fully penetrant terminal phenotype (Fig. 1). Other developmental processes, such as pharyngeal pumping, muscle twitching, gut differentiation, and cuticle formation characteristic of later embryonic stages, appear to proceed normally, and the embryos eventually hatch.

ca201 was mapped to the unc-57 unc-38 interval on linkage group I (LGI). We showed subsequently that ca201 fails to complement five alleles of the let-502 gene, isolated previously in a saturation screen of LGI left (Howell and Rose 1990). One let-502 allele (h835) causes an embryonic phenotype identical to that of ca201 and a second allele (h783) arrests slightly later; we refer to embryonic arrest as the "strong" phenotype. The other three alleles (h392, h509, and h732) lead to sterile adults (Fig. 1G), which we refer to as the "weak" phenotype. The germ line in these animals appears disorganized, but occasional oocytes and dead embryos can be detected. $h 392, h 509$, and $h 732$ adult animals are shorter than normal, often show a rolling phenotype (Rol) and have alae defects. Alae are longitudinal ridges of cuticle that cover the entire apical surface of the lateral seam cells in adult animals (Singh and Sulston 1978); alae are often branched in these three mutants (Fig. 1F,H). Overall, the mutant phenotypes are consistent with a role for let-502 in hypodermal development.

let-502 alleles are gain-of-function mutations with both maternal and zygotic activity

When ca201/+ males are crossed to hermaphrodites of

\section{wildtype}

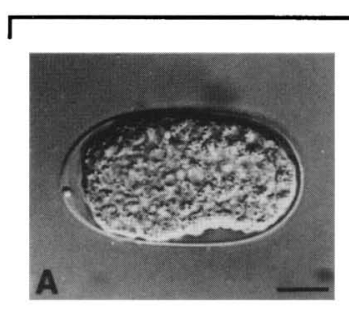

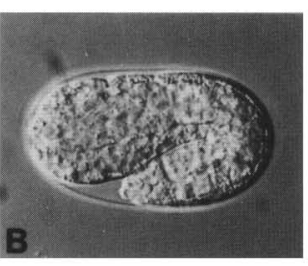
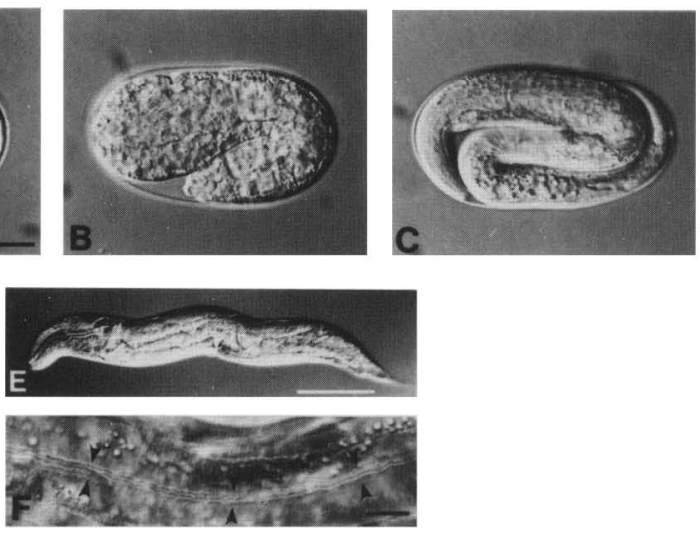

\section{let-502}

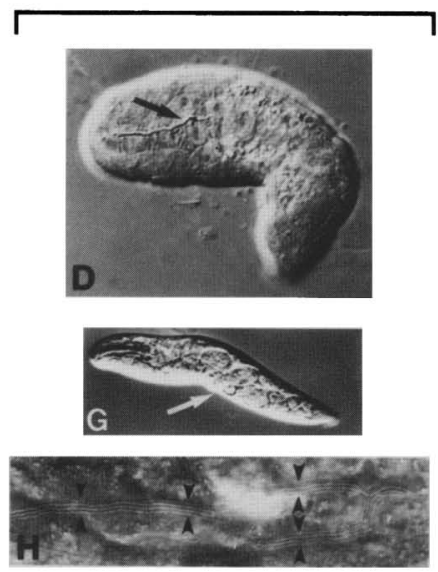

Figure 1. Phenotypes of homozygous let-502 animals suggest elongation defect. Wild-type C. elegans embryos are shown just before $(A)$, during early $(B)$, and after $(C)$ elongation. After the hypodermal cells enclose the embryo, elongation leads to an approximately fourfold increase in bodylength and threefold decrease in circumference (Priess and Hirsh 1986). A C. elegans embryo homozygous for ca201 is shown in $D$. The pharyngeal lumen is indicated by the arrow. A $d p y-5$ animal is shown in $E$, and part of the alae are visible as ridges on the lateral side of the hypodermis (arrowheads, F). Animals homozygous for $d p y-5$ and the $h 392, h 509$, and $h 732$ alleles arrest as short sterile adult worms ( $h 509$ is shown in $G$ ) and frequently show branched alae (arrowheads, $H$ ). Note that the animal shown in $G$ is shortened beyond that caused by the $d p y-5$ mutation present in the animal shown in $E$. A shortened phenotype is also seen in animals where the $h 392, h 509$, or $h 732$ alleles are not linked to $d p y-5$ (data not shown). Occasionally a few dead eggs, including some with a ca201-like phenotype (white arrow), are contained within adult let-502(h509) worms (G). Embryos and adult worms are oriented with dorsal at top and anterior to the left. Bar, $10 \mu \mathrm{m}(A-D, F, H)$ and $100 \mu \mathrm{m}(E, G)$. 
the deficiency strain $h D f 6 /+($ Table 1 , line 1$)$, the resulting ca201/hDf6 progeny display variable abnormal morphologies (Vabs) such as shortened and misshapen bodies, a Rol phenotype, and arrest stages that vary from mid-larvae to sterile adults. All these phenotypes are weaker than those associated with the ca201/ca201 selfprogeny of ca201/+ hermaphrodites. This indicates that ca201 is not a null allele and likely has gain-of-function properties.

The reciprocal cross, in which $h D f 6 /+$ males are crossed to ca201/+ hermaphrodites (Table 1, line 2), gives rise to embryos showing the early elongation arrest typical for homozygous ca201 progeny. This suggests that ca201 shows maternal effects resulting in earlier embryonic arrest, because the progeny genotypes of these two crosses (Table 1, cf. lines 1 and 2) are identical but differ in the origin of the ca201 allele (i.e., maternal or paternal). Maternal expression of let-502 becomes more evident when the progeny of let-502(h392, h509, or h732)/let-502(ca201)/+ animals are examined (h509 is shown as an example in Table 1, line 3): homozygous $h 392, h 509$, or $h 732$ progeny always arrest at the early elongation stage, with a phenotype identical to that of homozygous ca201 progeny, rather than as sterile adults.

When paternally derived ca201 (from ca201/+ males) is combined with any of the other let-502 alleles (from let-502/+ hermaphrodites; an example for the late arresting allele h509 is shown in Table 1, line 4), all of the resulting animals arrest at preadulthood stages. This indicates that all let-502 alleles, not just ca201, differ from deficiencies and so are non-null and likely gain-of-function mutations (Table 1, cf. lines 1 and 4). This is also true for ca201sb54, a cis-linked revertant of ca201 (Table 1 , line 5; see below). The gain-of-function nature of the let-502 mutations is further supported by gene dosage experiments, in which the relative amounts of let502(ca201) and wild-type let-502 are varied (Table 1, lines 6 and 7). let-502(ca201)/+ animals only occasion- ally show aberrant phenotypes such as Vab or Rol; in contrast, let-502(ca201)/let-502(ca201)/+ animals display frequent $\mathrm{Vab}$ or Rol phenotypes.

In summary, the let-502 mutations all have gain-offunction properties and show both maternal and zygotic effects. The early embryonic arrest phenotype requires maternal heterozygosity for a strong let-502 allele, in addition to the absence of let-502(+) function in the zygote. Both weak and strong alleles appear to have lost let-502|+| activity and the dominant maternal effects indicate that weak and strong alleles probably antagonize wild-type product, that is, the mutant products act in an antimorphic fashion. In a later section, we will show that these genetic properties are consistent with the molecular nature of the different mutations.

\section{Cloning of let-502}

The correlation between the genetic and physical maps of the C. elegans genome (Waterston and Sulston 1995) was used to clone the let-502 gene. Cosmids located within the unc-57 unc-38 interval (Fig. 2A) were tested for transformation rescue of let-502(ca201). Two overlapping cosmids (K06G1 and $\mathrm{C} 10 \mathrm{H} 11$ ) rescued the embryonic lethal phenotype to sterile adults, whereas 12 other cosmids did not. A 14-kbp ClaI fragment from K06G1 was subcloned and deletion derivatives thereof tested for transformation rescue (Fig. 2B). A 7.1-kbp EcoRV-XhoI subclone was the smallest fragment identified that could still reliably rescue let502(ca201). Using this subclone as a probe, 11 nested cDNAs were isolated. The longest of these cDNAs was 4275 bp lexons in Fig. $2 \mathrm{Cl}$ and a translational fusion of upstream let-502 genomic DNA with this cDNA rescued the ca201 mutant phenotype, thereby confirming the gene's identity.

The longest 1et-502 cDNA and the 10.4-kbp EcoRV-

Table 1. Genetic analysis of let-502

\begin{tabular}{|c|c|c|c|}
\hline \multicolumn{2}{|r|}{$\mathrm{F}_{1}$} & \multicolumn{2}{|r|}{$\mathrm{F}_{2}$} \\
\hline genotype & phenotype $^{\mathrm{a}}$ & genotype & phenotype \\
\hline$c a 201($ む) $/ h D f 6$ & Vab, Rol, sterile & - & - \\
\hline$h D f 6(\delta) / c a 201$ & Let (early morphogenesis) & - & - \\
\hline ca201/h509/+ ${ }^{\mathrm{b}}$ & occasional Vab and Rol & $h 509 / h 509^{c}$ & Let (early morphogenesis) \\
\hline ca201(0)/h509 & Let (variable) & - & - \\
\hline ca201(ठ)/ca201sb54 & Let (variable) & - & - \\
\hline $\mathrm{ca} 201 /+$ & wild type, occasional Vab and Rol & $\mathrm{ca} 201 / \mathrm{ca} 201$ & Let (early morphogenesis) \\
\hline $\mathrm{ca} 201 / \mathrm{ca} 201 /+^{\mathrm{b}}$ & frequent $\mathrm{Vab}$ and Rol; low brood sizes & ca201/ca201 & Let (early morphogenesis) \\
\hline ca201sb54(む)/hDf6 & Vab, Rol, sterile & - & - \\
\hline
\end{tabular}

A to symbol behind the allele designation indicates the paternal allele. Phenotypical designations are Vab (variable abnormal morphology), Rol (rolling, twisting movement), and Let (lethal = arrest before adulthood).

${ }^{\text {a }}$ Phenotypes were $100 \%$ penetrant except when otherwise noted (occasional $=<10 \%$; frequent $=>10 \%$; variable $=$ arrest stages varied between early morphogenesis to later larval stages; most animals arrested at early to mid-larval stages).

${ }^{b}$ Wild-type let-502|+| was supplied by the free duplication $s D p 2$.

${ }^{c}$ Homozygous $h 509$ animals were identified indirectly by the absence of sterile adult Dpy animals (h509 is linked to dpy-5) and a corresponding increase in the number of embryos arrested at early morphogenesis (ca201/ca201; ca201/h509; h509/h509). 


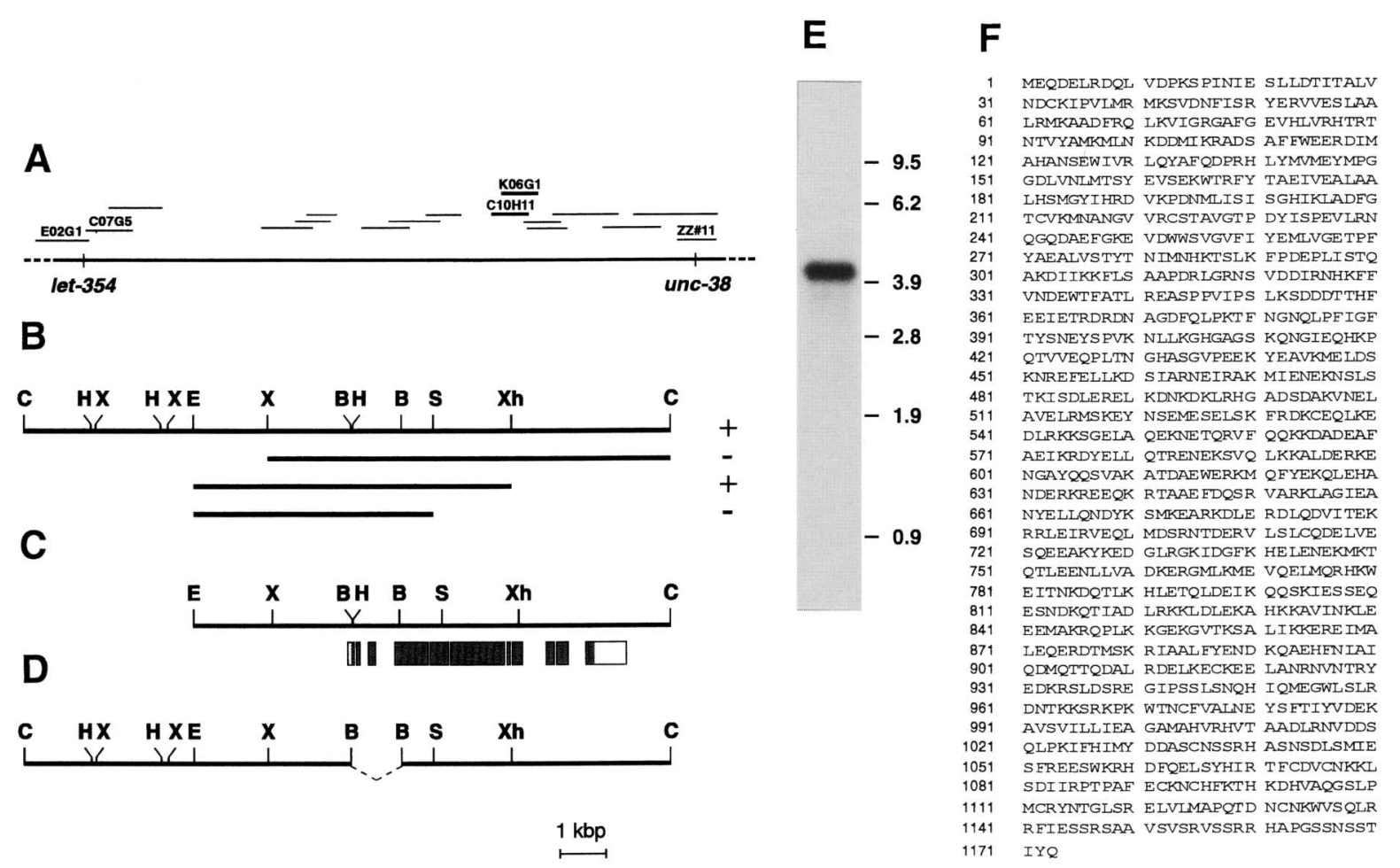

Figure 2. Analysis of the let-502 gene. (A) Schematic representation of the genetic and physical maps between let-354 and unc-38. unc-57 maps between let-354 and unc-38 but has not yet been placed on the physical map. The coding sequence for let-354 is probably contained on cosmids E02G1 and C07G5 (J. Lye, pers. comm.), thereby establishing the leftward boundary for cosmids that could contain let-502. unc-38 is partially located on ZZ\#11 (J. Lewis, pers. comm.) and defines the rightward boundary. Fourteen cosmids (listed in Materials and Methods) that were tested for transformation rescue are shown. $(B)$ A 14-kbp ClaI fragment derived from cosmid K06G1 containing let-502 and deletion constructs thereof. The ability for transformation rescue is indicated by + or Restriction sites shown are BamHI (B), ClaI $(\mathrm{C}), E c o R V(E), H i n d I I I(H), S p h I(S), X b a I \mid X)$, and XhoI (Xh). Not all restriction sites for $S p h I$ are indicated. $(C)$ The sequenced genomic fragment and the intron/exon structure of let-502. Exons are shown as boxes, and the coding sequence is shaded. (D) In-frame deletion within the kinase domain of LET-502. $(E)$ Northern blot analysis using poly $(A)^{+}$ mRNA from wild-type animals and let-502 cDNA as a probe. $(F)$ Predicted protein sequence for LET-502.

ClaI genomic fragment were sequenced and the deduced intron/exon structure is shown in Figure 2C. The genomic sequence shows a potential splice acceptor site $10 \mathrm{bp}$ upstream of the $5^{\prime}$ end of the longest cDNA. RT-PCR and sequence analysis (data not shown) confirmed that at least some of the let-502 mRNA is trans-spliced to SLl at this site (Krause and Hirsh 1987). When the cDNA was used to probe a Northern blot of mixed-stage $C$. elegans mRNA, a single band of $4.3 \mathrm{~kb}$ was detected (Fig. $2 E)$, indicating, together with the SLl result, that the sequenced let-502 cDNA is close to full length. The first in-frame ATG codon in the cDNA sequence is located at nucleotide 49 and leads to a predicted protein product of 1173 amino acids (Fig. 2F).

\section{Let-502 belongs to a family of Rho-binding kinases} and is similar to human DM-kinase

A database search revealed that the Let-502 product is predicted to be a Ser/Thr kinase with the highest degree of similarity to three recently identified Rho-binding kinases: human p160 ROCK (Ishizaki et al. 1996), rat ROK $\alpha$
(Leung et al. 1995), and bovine Rho-kinase (Matsui et al. 1996) (Fig. 3A). A comparison of kinase domains indicates that Let-502 and these Rho-binding kinases also show significant similarity to DM-kinase (Brook et al. 1992; Fu et al. 1992; Mahadevan et al. 1992). Several other kinases, such as the Drosophila tumor suppressor Wts (Justice et al. 1995) and Neurospora COT1 (Yarden et al. 1992), also belong to this subfamily, as noted previously by Justice et al. (1995); however, their similarities to Let-502, the Rho-binding kinases, and DM-kinase are confined to the kinase domain.

The spacing between the kinase sub-domains supports the grouping together of LET-502, Rho-binding kinases, and DM kinase. As diagramed in Fig. 3B, LET-502 and the Rho-binding kinases have a deletion of one residue and DM-kinase an insertion of one residue between subdomain $\mathrm{V}$ and $\mathrm{VIa}$, compared with the other kinases. LET-502, the Rho-binding kinases, and DM-kinase have an insertion of four amino acids between subdomains VII and VIII, whereas the other kinases have insertions of 58 to 71 amino acids. Between subdomains VIII and IX, LET-502, the Rho-binding kinases and DM-kinase have insertions of four (LET-502, Rho-binding kinases) or 
A

C.elegans LET-502

Human p160 ROCK

Rat ROK $\alpha$

Bovine Rho-kinase

Human DM-kinase

Drosophila Wts

Neurospora COT1

Bovine cAPK- $\alpha$
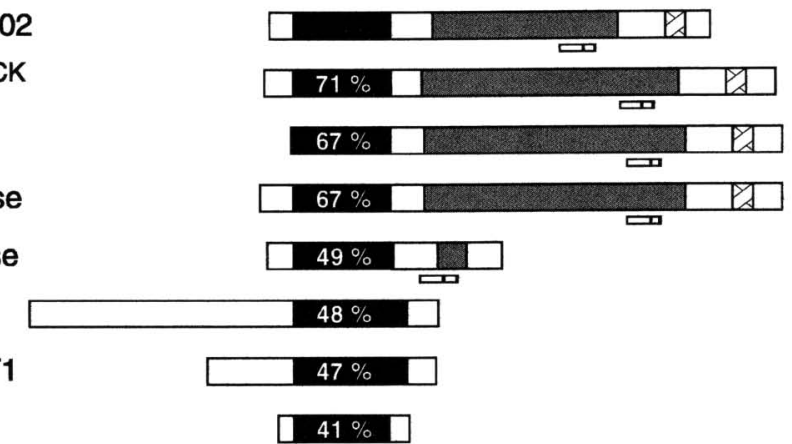

$49 \% \quad \square$

$41 \%$

B

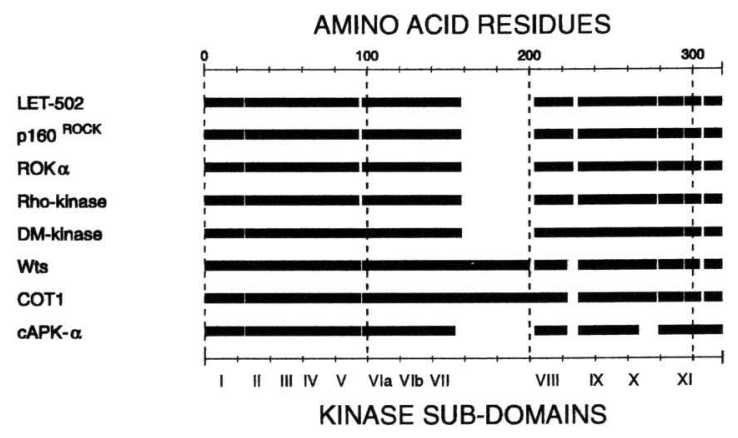

C

D

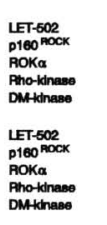

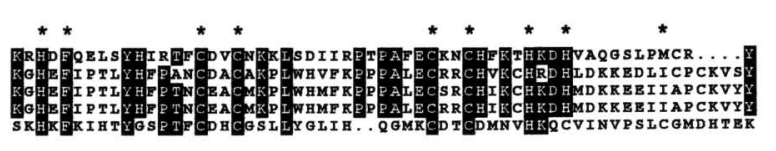

$1058-1114$
$1227-1287$ $1227-1287$
$1173-1233$ $1173-1233$
$1259-1319$
$100-158$ $100-158$

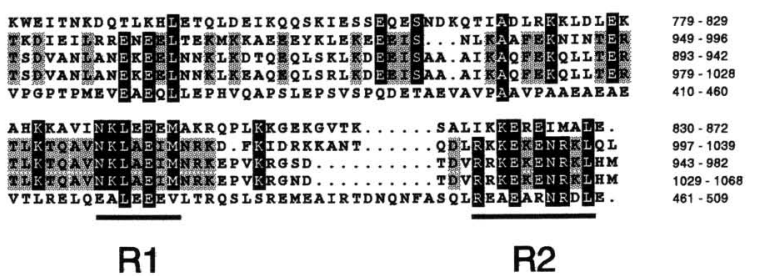

Figure 3. LET-502 belongs to a subfamily of Ser/Thr kinases. (A) Schematic sequence alignment of representative kinases within this subfamily. Bovine cAPK- $\alpha$ is included as the canonical member of the Ser/Thr kinases (Shoji et al. 1983). The following kinases belong to the same subfamily but are not included in the figure: the Ndr-kinases (Millward et al. 1995), fungal TB3 (T.L. Buhr, G.M. Truesdell, and M.B. Dickman, unpubl., GenBank accession no. U14989), and three plant kinases (B. Baur, K. Winter, K. Fischer, and K. Dietz, unpubl., GenBank accession nos. Z30329 and Z30330; Y. Huang, J. Wan, K. Ko, and D.T. Dennis, unpubl., GenBank accession no. $X 71057$ ). Sequences are aligned at the amino termini of the kinase domains (shown in black). Numbers indicate percent amino acid identity in the kinase domains compared with Let-502. Shading indicates segments predicted $(>50 \%$ probability) to adopt coiled-coil structures (Lupas 1996). The hatched segment shows the Cys/His-rich region. Small rectangles beneath the coiled-coil regions represent the potential Rho-binding domains, and black squares contained within mark the two regions of highest similarity (see Fig. 3D). $(B)$ Schematic representation of kinase domains. Black bars represent the aligned sequences and gaps reflect insertions in at least one of the sequences within this group. The top scale gives the number of amino acid residues; the bottom scale shows the relative location of the kinase subdomains (Hanks and Hunter 1995). (C) Alignment of the Cys/Hisrich regions. PKC $\alpha$ is included as a protein containing the conventional zinc-binding Cys-rich motif (Parker et al. 1986; Ahmed et al. 1991). Invariant residues in the Cys/His motif of $\mathrm{PKC} \alpha$ and related proteins are indicated by asterisks above the sequence. Residues are shown white on black when at least four of five at a given position are identical. (D) Alignment of potential Rho-binding fragments. Residues identical between pl $60^{\mathrm{ROCK}}$, ROK $\alpha$, and Rho-ki-nase are shaded or are depicted white on black when at least four of five residues at a given position are identical. Two segments of higher identity are underlined and labeled R1 and R2, respectively. Residue positions are given to the right of the sequences in $C$ and $D$.

seven (DM-kinase) amino acids relative to the other kinases and CAPK- $\alpha$.

LET-502, the Rho-binding kinases, and DM-kinase also show similarity outside the kinase domain. Within the 67 amino acids at the amino terminus where LET502, p160 ROCK, Rho-kinase, and DM-kinase overlap, LET-502, p160 ROCK, and Rho-kinase, are $34 \%(23 / 67)$ identical. In this same amino-terminal region, DM-kinase is $28 \%(19 / 67)$ identical to at least two of the other three kinases. In the region carboxy-terminal to the kinase domain, LET-502, the Rho-binding kinases, and DM-kinase all are predicted to form coiled-coil structures (Lupas 1996; see Fig. 3A).
LET-502 and the Rho-binding kinases contain a conserved Cys/His-rich motif $\sim 125$ residues downstream of the predicted carboxy-terminal end of the coiled-coil domain (Fig. 3C). The distribution of Cys and His residues is similar but not identical to that found in the zincbinding motif of $\mathrm{PKC} \alpha$ and other related proteins (Ahmed et al. 1991; Leung et al. 1995). This Cys/His motif is not apparent in DM-kinase.

Based on sequence similarities, we predict that LET502 will interact with a protein related to the small GTPase Rho. ROK $\alpha, \mathrm{p} 160^{\mathrm{ROCK}}$, and Rho-kinase were identified because of their ability to bind Rho (Leung et al. 1995; Ishizaki et al. 1996; Matsui et al. 1996). The 
Rho-binding site in ROK $\alpha$ lies in a 90-amino-acid segment within the coiled-coil domain (Fig. 3A; Leung et al. 1995); the Rho-binding site of Rho-kinase has also been shown to lie within the coiled-coil region (Matsui et al. 1996). When the Rho-binding sequence of $\mathrm{ROK} \alpha$ is aligned with the other kinases (Fig. 3D), two segments become apparent that show a high degree of identity between p160 ${ }^{\mathrm{ROCK}}, \mathrm{ROK} \alpha$, and Rho-kinase, suggesting that one or both of these segments participate in Rho binding. Within these segments two short regions of higher identity (Fig. 3D, R1 and R2) are found between LET-502 and the Rho-binding kinases; these regions are located at similar positions relative to the carboxy-terminal end of the predicted coiled-coil domain. DM-kinase also contains a similar region within its coiled-coil domain (Fig. 3D), implying that DM-kinase may also bind Rho or a related protein.

Strong let-502 mutations alter the kinase domain and can be suppressed by a carboxy-terminal deletion that removes the predicted Rho-binding site

The sequences of the let-502 mutations were determined. The molecular defects can be placed into two classes, correlating with the weak and strong phenotypes (Fig. 4). The three alleles that confer a strong phenotype (ca201, h783, and h835) each contain a missense mutation in a highly conserved residue of the kinase domain (for review of kinase domains, see Taylor et al. 1992; Hanks and Hunter 1995). ca201 has a Gly $\rightarrow$ Glu exchange at residue 317 in subdomain XI, $h 783$ has a Gly $\rightarrow$ Glu exchange at residue 228 in subdomain VIII, and $h 835$ has a Gly $\rightarrow$ Asp substitution at residue 150 in subdomain V. In contrast, the three alleles that confer the weak phenotype each contain a mutation that would lead to a truncated LET-502 protein: h392 contains a nonsense mutation, $h 509$ contains a mutation in a splice donor site, and $h 732$ contains a mutation in a splice acceptor site. Because of the severity of these truncations (the resulting polypeptides are predicted to contain only 299,104 , and 50 amino-terminal amino acids; see legend to Fig. 4), h392, h509, and $h 732$ alleles are unlikely to produce wild-type activity. $h 509$ and $h 732$ have to be treated with caution, though, because it has been shown that splicing "readthrough" can occur (see, e.g., Aroian et al. 1993). Nevertheless, $h 509$ and $h 732$ demonstrate gain-of-function characteristics arguing that wild-type product is not made. At least in the case of h392 it appears that growth to sterile adults for homozygous h392 animals is a result of maternal rescue by wild-type LET502 product.

The above mutation data can be interpreted to suggest that the strong phenotype requires an inactive kinase domain together with some "activity" elsewhere in the protein. We have two lines of evidence that support such a model.

The first test of the model was to transform wild-type animals with an in-frame deletion that should eliminate LET-502 kinase activity 156 residues from the aminoterminal region and 69 residues from the kinase domain were removed, thereby eliminating kinase subdomains I, II, III, and IV, thought to participate in ATP binding) but that should retain all sequences of the coiled-coil domain (see Figs. 2D and 4). Twenty-one injected wild-type animals gave rise to 51 arrested $F_{1}$ embryos, most of which $(>90 \%)$ showed early elongation arrest typical for animals homozygous for the strong alleles; some embryos arrested at even earlier stages (data not shown).
Figure 4. Different molecular structures of strong and weak LET-502 mutants. Sequence changes for the strong let-502 alleles [arrested embryos: ca201, h783, h835, and in-frame deletion [see Fig. 2D)] or weak alleles (sterile adults: $h 392$, $h 509, h 732$, and ca201sb54) are shown compared with a schematic representation of the wild-type sequence (see Fig. 3A). Amino acids are given in the single-letter code, and numbers indicate either the affected residues or the predicted length of truncated proteins. The mutational changes leading to the truncations are as follows: $\mathrm{G} \rightarrow \mathrm{A}$ transition in $h 392$ that changes $\operatorname{Gln}^{300}$ into a stop codon. $h 509$ encodes a $G \rightarrow A$ transition at the invariant $G$ of the splice donor in intron 3. Assuming that the next possible splice donor site is used (Krause 1995), this leads to a predicted protein containing 104 amino-terminal residues of LET502 , one extra carboxy-terminal residue, and a stop codon. $h 732$ encodes a $G \rightarrow A$ transition at the invariant $G$ of the splice acceptor in intron 2 . If the next possible splice acceptor is used, this protein would contain only 50 amino-terminal residues of LET-502, two extra carboxy-terminal residues, and a stop codon.
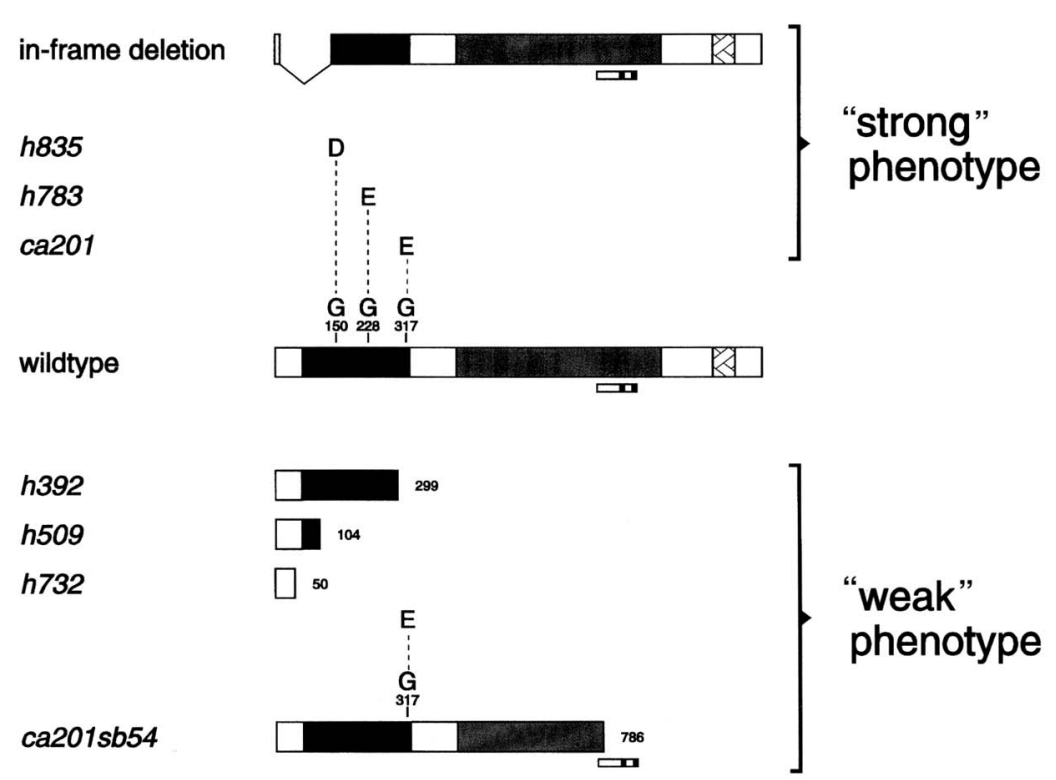
Thirty-seven $F_{1}$ rollers grew to fertile adults (presumably as a result of lower expression of the let-502 deletion transgene relative to their ca201-like sibs) and two heritable lines were produced. Both lines produced $1 \%-5 \%$ progeny with a ca201-like phenotype as well as progeny showing $\mathrm{Vab}$ and Rol phenotypes. Arrested ca201-like embryos were never observed in control injections using let-502(+) DNA.

The second line of evidence that the strong phenotype is caused by kinase domain inactivation within an otherwise intact LET-502 protein comes from an intragenic suppressor $(c a 201 s b 54)$ that converts the strong to the weak phenotype. Genetic manipulations show that ca201sb54 retains weak gain-of-function characteristics and does not seem to be a null allele (Table 1, lines 5 and 8). In addition to the ca201 mutation, ca201sb54 contains a stop codon in the coiled-coil domain, leading to a truncated protein of 786 amino acids (and lacking both the putative Rho-binding site and Cys/His-rich motif shown in Fig. 4).

\section{let-502 is expressed in hypodermal seam cells at the time of embryonic elongation}

To determine the expression pattern of the let-502 gene, a lac $Z$ reporter gene was fused to $6 \mathrm{kbp}$ of let-502 5'flanking sequences (shown previously to be capable of rescuing the let-502 phenotype when fused to a let-502 cDNA; see Materials and Methods for details) and transgenic lines were established. Strong expression of the let-502::1acZ fusion is observed in the lateral hypodermal seam cells at the onset of the elongation phase of morphogenesis (Fig. 5), corresponding to the time of early elongation arrest of let-502(ca201) (Fig. 1). let-502 expression was also visible in the seam cells of early elongation embryos using RNA in situ hybridization (B. Goszczynski, pers. comm.), suggesting that the observed let-502::1acZ expression pattern indeed reflects native let-502 expression. Other hypodermal cells in the embryo show weaker expression of the reporter construct (data not shown), but these cells have not yet been identified precisely.

\section{Isolation of let-502 suppressors}

In a screen for suppressors of let-502(ca201) embryonic lethality, one intragenic ( $c a 201 s b 54$; see above) and two recessive extragenic suppressors $(s b 55$ and $s b 56)$ were identified. All three mutations convert the strong let-502 phenotype into a weak phenotype. In the absence of the ca201 allele, homozygous sb55 animals are morphologically wild type but show leaky temperature-sensitive maternal-effect embryonic lethality; homozygous sb56 animals are sterile adults containing apparently disorganized gonads and appear slightly longer and thinner than normal (Table 2, lines 1-4).

sb56 fails to complement sb55 for suppression of ca201 (data not shown) and for maternal effect lethality (Table 2, cf. lines 2 and 5). Suppression does not appear to be allele-specific because $s b 55$ rescues the embryonic le-
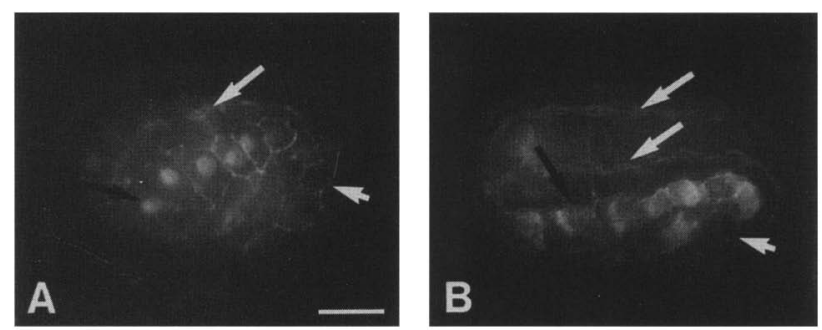

Figure 5. Expression of let-502 reporter constructs. $\beta$-Galactosidase staining in transgenic let-502::1acZ animals. Embryos were analyzed by indirect immunofluorescence after simultaneous staining with three monoclonal antibodies. MH27 stains the belt desmosomes outlining the hypodermal cells (short white arrows; Francis and Waterston 1991). DM5.6 stains body wall muscle myosin located in muscle quadrants just beneath the hypodermal cells (long white arrows; Miller et al. 1983). The dorsal left $(A)$ and the dorsal left and right $(B)$ muscle quadrants are visible in the focal planes shown. Anti- $\beta$-galactosidase antibody stains either the nuclei of the seam cells (nuclear localized let-502::1ac $Z$ reporter construct) as shown in $A$ or the seam cell cytoplasm (non-nuclear localized let-502::1acZ reporter construct) as shown in $B$. One staining seam cell for each embryo is indicated by a black arrow. Occasional seam cells do not stain for $\beta$-galactosidase, presumably because of mosaic loss of the extrachromosomal element containing the reporter constructs. Less intense staining in other hypodermal cells can also be detected (data not shown). Embryos are oriented with dorsal at the top and anterior to the left. Both wild-type embryos are at early elongation, with $B$ presenting a more dorsal aspect than $A$ (see Fig. 1). Bar, $10 \mu \mathrm{m}$.

thality of the other strong let-502 alleles, $h 783$ and $h 835$. Neither $s b 55$ nor $s b 56$ can rescue the adult sterility of the weak alleles $h 509$ and ca201sb54 (data not shown). Both $s b 55$ and $s b 56$ likely represent loss-of-function alleles. The two mutations were found among 6800 mutagenized genomes, consistent with the C. elegans forward

Table 2. Genetic analysis of extragenic let-502 suppressors

\begin{tabular}{lcc}
\hline & \multicolumn{2}{c}{ Percent hatching } \\
\cline { 2 - 3 } Genotype & $20^{\circ} \mathrm{C}$ & $25^{\circ} \mathrm{C}$ \\
\hline$s b 55 /+$ & 98.0 & 94.1 \\
$s b 55$ & 59.5 & 25.2 \\
$s b 56 /+$ & 95.0 & 92.6 \\
$s b 56$ & $-^{\mathrm{a}}$ & $-^{\mathrm{a}}$ \\
$s b 55 / s b 56$ & 20.4 & $3.6^{\mathrm{b}}$ \\
sb55/mnDf61 & $26.0^{\mathrm{c}}$ & N.D. \\
ca201/+;sb55 & 86.6 & 76.4 \\
ca201/+;sb55/sb56 & 71.5 & N.D. \\
\hline
\end{tabular}

At least 500 embryos from hermaphrodites of each genotype were assayed for hatching per data point. $s b 55 / s b 56$ and $s b 55 /$ $m n D f 61$ were also Unc-4, but this did not alter hatching percentages significantly (data not shown).

${ }^{\text {aS }}$ terile.

${ }^{\mathrm{b}}$ Most of the nonhatching embryos arrested between early and mid elongation.

${ }^{\mathrm{c} C o r r e c t e d}$ for $25 \%$ dead homozygous $m n D f 61$.

d(N.D.) Not determined. 
mutation rate of $1 / 2000$ to $1 / 5000$ after standard ethylmethane sulfonate (EMS) mutagenesis (Anderson 1995). Both $s b 56$ and a deficiency of the region ( $m n D f 61)$ exacerbate the maternal-effect lethality of $s b 55$ to a similar degree, indicating that $s b 55$ may be hypomorphic and that $s b 56$ is near-null (Table 2, cf. lines 5 and 6).

Thus, it appears that loss or reduction of let-5021+1 activity can be compensated by a reduction of the gene activity defined by $s b 55$ and $s b 56$ during embryogenesis. Consistent with this suggested compensation, the presence of one dose of the strong (likely antimorphic) allele ca201 partially alleviates the maternal-effect lethality of $s b 55 / s b 55$ (Table 2, cf. lines 2 and 7 ) or $s b 56 / s b 55$ (Table 2 , cf. lines 5 and 81 .

Both $s b 55$ and $s b 56$ map to the let-23 unc- 4 interval on LGII. We tested known genes within this interval for allelism with the let-502 suppressors. sb55 and sb56 failed to complement the maternal-effect lethality of mel-11(it26), a gene identified by Kemphues et al. (1988) in a saturation screen of LGII. mel-11(it26) also suppresses let-502(ca201). The detailed genetic interactions will be described elsewhere (A. Wissmann, J. Ingles, J.D. McGhee, and P.E. Mains, in prep.).

The extragenic suppressors of let-502 are in a gene coding for a protein with high similarity to myosin phosphatase regulatory subunits

Open reading frames (ORFs) predicted by the genomic sequence (Waterston and Sulston 1995) in the let-23 unc-4 interval were inspected for candidates that might interact with let-502. One predicted ORF (C06C3.1) showed significant sequence similarity to a myosin phosphatase regulatory subunit (Chen et al. 1994; Shimizu et al. 1994), of the type known to be essential for contraction in smooth muscles (for review, see Erdödi et al. 1996). We found that transformation with the C06C3.1-containing cosmid F42A 8 does rescue $s b 56$ sterility, as does a 13.3-kb NruI-BamHI subclone that contains only $\mathrm{C} 06 \mathrm{C} 3.1$. The intron/exon structure of C06C3.1 shown in Figure 6A is supported by the structure of several cDNAs identified in the region and sequencing of PCR-derived cDNAs (see legend to Fig. 6A). An NruI-BamHI subclone with a frameshift mutation in the third exon fails to rescue sb56 sterility. Furthermore, the sequence of a PCR-derived cDNA for the C06C3.1 ORF from $s b 55$ shows a G $\rightarrow$ A transition (see below) as expected from EMS mutagenesis (Anderson 1995). Taken together, these data strongly suggest that C06C3.1 is mel-11.

Conceptual translation of mel-11 (Fig. $6 \mathrm{~B}$ ) predicts a 1016-amino-acid protein (MEL-11) with similarity to the regulatory subunit of smooth muscle myosin phosphatase M110 from rat (Chen et al. 1994) and M130 from chicken (Shimizu et al. 1994; Fig. 6C). MEL-11, M110, and M130 contain stretches of significant similarity at both the amino and carboxyl termini, further suggesting that the ORF has been established correctly. At the amino terminus, MEL- 11 contains seven predicted ankyrin repeats that are $47 \%$ identical (108/231 residues)

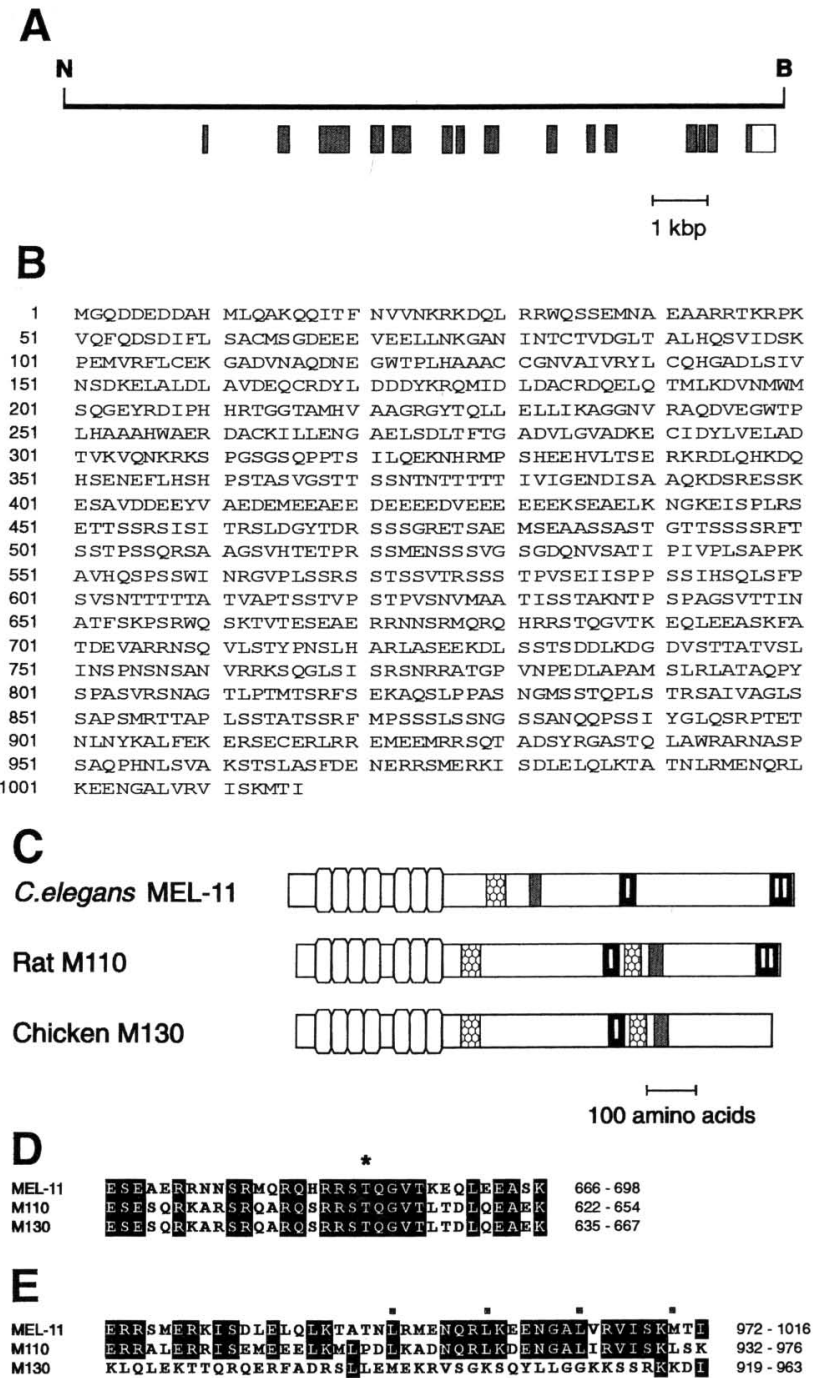

Figure 6. MEL-11 belongs to a family of myosin phosphatase regulatory subunits. $(A)$ The predicted intron/exon structure of mel-11. The rescuing genomic NruI-BamHI fragment is depicted as a line with predicted exons (boxes) below. Shading indicates predicted translated regions. Exons were established based on ORFs suggested by consensus sequences for $C$. elegans splice acceptor and donor junctions (Krause 1995), by partial cDNA sequences (YK550 group; Y. Kohara, pers. comm.), and by sequencing of PCR-derived cDNAs. $(B)$ The predicted protein sequence for MEL-11. (C) Schematic representations of MEL-11, M110 (Chen et al. 1994), and M130 (Shimizu et al. 1994). Sequences are aligned at the first residue of the first of the ankyrin repeats (indicated as elongated octagons). Two highly conserved regions (see text) are shown as black boxes (labeled I and II). Ser/Thr-rich regions /stretches of $>20$ residues with $>70 \%$ Ser and Thr) are shaded. Acidic clusters (stretches of $>30$ residues with $>50 \%$ Asp or Glu) are depicted as small hexagons. $(D)$ Alignment of conserved region I. Residues identical in all three sequences are shown white on black. The Thr residue shown to be the principal target for phosphorylation in M130 (see text) is indicated by an asterisk. (E) Alignment of carboxyl termini. Residues are shown white on black when at least two out of three are identical. For MEL-11 and M110, this segment corresponds to region II. Residues that could participate in the leucine zipper motif for MEL-11 and M1 10 are indicated by shaded boxes above the sequence (Hu et al. 1990; Bikle et al. 1993). Residue positions are given to the right of the sequences in $D$ and $E$. 
to the ankyrin repeats of M110 and M130. Moreover, all three proteins contain a 27 -amino-acid spacer between ankyrin repeats 4 and 5 . The next best match to MEL-11 in the database is to human brain ankyrin (Otto et al. 1991), which shows $31 \%$ identity within the ankyrin repeats but lacks the 27 -amino-acid spacer and has a total of 22 ankyrin repeats compared with the conserved seven ankyrin repeats in MEL-11, M110, and M130. A database search using MEL-11 sequences carboxy-terminal to the ankyrin repeats again detects M110 and M130 as the most similar proteins, although this similarity is limited (see below).

Figure 6, D and E, shows that MEL-11, M110, and M130 contain two further regions of conserved sequence. Region 1 (Fig. 6D; 20/33 residues identical among all three proteins) contains a block of eight identical residues, including the Thr that has been shown to be the major site for M130 in vitro phosphorylation (Ichikawa et al. 1996). The first four residues of this block (RRST) correspond to the consensus site recognized by cAMP-dependent protein kinase (Kennelly and Krebs 1991). Region 2 is shared between MEL-11 and M110 (26/45 identical residues) but not M130 (Fig. 6E) and lies at the immediate carboxyl terminus of these proteins. It contains a leucine zipper motif described previously (Chen et al. 1994), indicating a possible role in proteinprotein interactions.

The mutation in mel-11(sb55) was identified as a nonsense mutation in which an arginine codon was changed to a stop codon at residue 772 of the protein. This mutation is located between regions 1 and 2 and the protein seems to retain some partial activity as suggested by the genetic evidence (see above).

\section{Discussion}

Midway through embryogenesis, the $C$. elegans embryo undergoes a dramatic morphogenetic transformation, changing from an ovoid ball of cells into a long, thin worm. A microfilament-dependent change in the shape of the hypodermal cells appears to be the principal driving force for this elongation (Priess and Hirsh 1986). C. elegans elongation may thus be a model for many other examples of animal morphogenesis that do not require cell divisions, cell growth, or cell rearrangements.

The let-502 gene affects hypodermal cell shape in C. elegans embryos

The following five observations support a role for the let-502 gene in the hypodermal cells shape changes that drive C. elegans embryonic elongation. (1) Strong let-502 alleles block elongation in homozygous embryos at the developmental stage when hypodermal cells begin to change shape (but do not affect markers of later differentiation). (2) Adult animals homozygous for the weak let502 alleles are shorter than wild type and show defects in the lateral alae (hypodermis). (3) Transgenic let-502::1 acZ reporter genes and let-502 mRNA are expressed in the hypodermal cells during embryonic elongation. (4) LET-
502 belongs to a subfamily of Ser/Thr kinases, many of which are known to be involved in cell shape changes in other systems (Yarden et al. 1992; Justice et al. 1995; Kimura et al. 1996). (5) Strong let-502 mutations are suppressed by mutations in a gene similar to the smooth muscle myosin phosphatase regulatory subunit, for which a regulatory role in cell contraction has been documented extensively (for review, see Erdödi et al. 1996).

\section{The LET-502 protein may interact with as many as three other factors}

The genetic properties and the molecular nature of the different let-502 mutations suggest that LET-502 may have three distinct interactions or functions. The first and most obvious interaction is with the substrate of the LET-502 kinase and this will be considered in the following section. Evidence for a second interaction or function comes from the strong let-502 phenotype, which appears to require an inactive kinase domain within the context of a normal carboxy-terminal region. This carboxy-terminal region includes the predicted Rho-binding site, as well as a Cys/His-rich motif. A third interaction or function of LET-502 in its amino-terminal region is indicated by the observation that even the weakest alleles, including one corresponding to only 50 amino acids, behave genetically like gain-of-function mutations.

let-502 seems to mutate easily to gain-of-function alleles, whereas null alleles have not been obtained so far. The prevalence of gain-of-function alleles may indicate that functionally inactivated LET-502 still has a high potential for interaction with other proteins (e.g., through the coiled-coil domain or the conserved aminoterminal region).

The proposed in vivo substrate for the LET-502 Ser/Thr kinase is MEL-11, which is similar to a myosin phosphatase regulatory subunit

We have shown that strong alleles of let-502 can be suppressed by mutations in the mel-11 gene, which encodes a gene similar to a myosin phosphatase regulatory subunit. From the genetic evidence alone, it is not possible to decide whether this suppression is a result of a direct interaction (e.g., MEL-11 is the substrate of LET-502) or an indirect interaction (e.g., the LET-502 kinase and the MEL-11 associated phosphatase compete for a common substrate such as $\operatorname{Ser}^{19}$ on myosin regulatory light chain; see below). Recently, evidence has been obtained suggesting that LET-502 could actually participate in both interactions. Kimura et al. (1996) have shown that Rhokinase, a candidate homolog of LET-502 in a vertebrate system, is capable of directly phosphorylating the equivalent phosphatase subunit M130 in vitro. Amano et al. (1996) have demonstrated that Rho-kinase can efficiently phosphorylate $\operatorname{Ser}^{19}$ on myosin regulatory light chain, thereby leading to actin activation of myosin ATPase. Thus, we propose that MEL-11 is an in vivo 
substrate for LET-502 kinase and that LET-502 may also phosphorylate $\operatorname{Ser}^{19}$ on myosin regulatory light chain.

A proposed pathway for cell shape change in C. elegans embryonic elongation

Our results lead us to propose a molecular pathway for changes in hypodermal cell shape, as diagramed in Figure 7. The different steps in this model are supported by our present data or are adapted from the well-studied field of smooth muscle biochemistry.

Members of the Rho family of GTPases /Cdc42, Rac, and Rho) play crucial roles in transducing signals that lead to reorganization of the cytoskeleton (for review, see Hall 1994; Chant and Stowers 1995). We suggest that a developmental signal that initiates hypodermal contraction acts through a Rho-like protein, by activating LET. 502 kinase, either by enhancing LET-502 enzymatic activity or by directing some subcellular localization. Small GTP-binding proteins from $C$. elegans have been identified biochemically (Chen et al. 1993a,b; Chen and Lim 1994), but no mutants are yet available to test for the predicted genetic interactions. Activated LET-502 then negatively regulates the activity of a smooth muscle-like myosin phosphatase complex by phosphorylating the regulatory subunit MEL-11, and may also directly phosphorylate $\operatorname{Ser}^{19}$ on myosin regulatory light chain. In smooth muscle, myosin regulatory light chain Ser $^{19}$ phosphorylation by MLCK causes contraction, whereas dephosphorylation by the phosphatase complex causes relaxation (for review, see Allen and Walsh 1994; Somlyo and Somlyo 1994).

Thus, we propose that Rho-activated LET-502 interactions lead to increased nonmuscle myosin regulatory light chain phosphorylation levels of $\operatorname{Ser}^{19}$ and therefore elongation (contraction) of the embryo (Fig. 7). Decreased LET-502 activity (strong let-502 mutants) results in lower Ser ${ }^{19}$ phosphorylation levels (attributable to higher activity of myosin phosphatase and/or reduced levels of Ser ${ }^{19}$ phosphorylation by LET-502), preventing hypodermal cell contraction. These let-502 mutations in turn can be suppressed by mel-11 mutations that presumably reduce phosphatase activity. Consistent with this view, an increase of MEL-11, supplied by a multicopy extrachromosomal array, has the opposite effect, enhancing the weak let-502(ca201sb54) mutation to result in early to mid-larval arrest (data not shown).

\section{Possible implications for human myotonic dystrophy}

Human myotonic dystrophy (DM) is an autosomal dominant disease that is typically associated with progressive muscle wasting and myotonia (for review, see Harper 1989|. Although symptoms in skeletal muscle function are most prominent, DM also causes defects in nonmuscle cell types. The disease has been linked to a CTG triplet expansion in the 3 '-untranslated exon of DM-kinase (Brook et al. 1992; Fu et al. 1992; Mahadevan et al. 1992); but despite recent advances with mouse models (Jansen et al. 1996; Reddy et al. 1996), the substrate of DM-kinase and the pathway in which DM-kinase functions are unknown.

Based on the sequence similarities between human DM-kinase, C. elegans LET-502, and the other members of this kinase family shown in Figure 3, we propose that DM-kinase may act in a pathway similar to that shown in Figure 7, to influence cytoskeletal organization and cell shape. In particular, we propose that DM-kinase may interact with a Rho-like small GTP-binding protein and that the normal substrate of DM-kinase may be a regulatory subunit of myosin phosphatase.

\section{Materials and methods}

Genetic techniques

C. elegans strains were maintained under standard conditions
Figure 7. Model for regulation of hypodermal seam cell shape in C. elegans. The model describing interactions of LET-502 and MEL-11 is described in the text. Nonmuscle myosin regulatory light chain ( $\mathrm{nmRLC}$ ) can be phosphorylated at $\operatorname{Ser}^{19}$ (indicated by circled $\mathrm{P}$ ) by MLCK. Recently it was shown that $\operatorname{Ser}^{19}$ can also be phosphorylated by the Rho-activated form of Rho-kinase (Amano et al. 1996), thus suggesting that activated LET-502 may have a dual function in phosphorylating both MEL-11 and nmRLC. Asterisks indicate activated protein forms. An early elongation embryo is shown at the bottom (relaxation), a postelongation embryo is depicted at the top (contraction). The lateral seam cells are outlined to indicate the cell shape changes that accompany elongation.

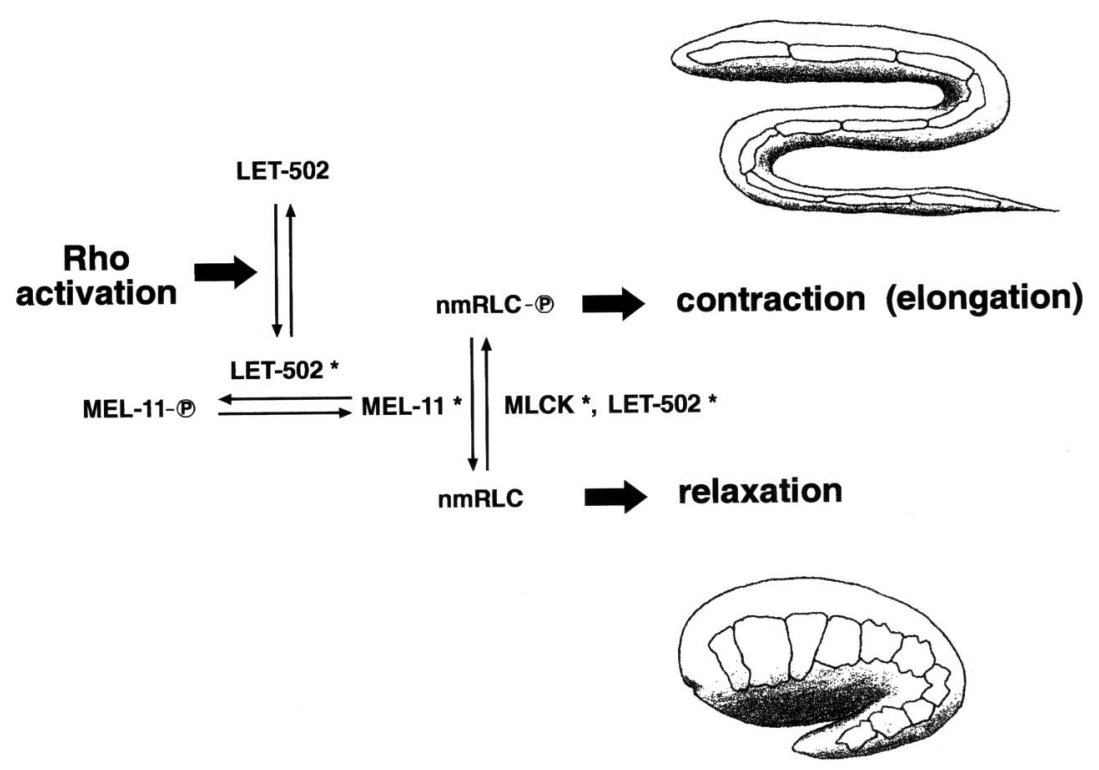


(Brenner 1974). To isolate elongation defective C. elegans mutations, 12,100 haploid genomes were mutagenized with 12.5 mM EMS (Brenner 1974) and $\mathrm{F}_{2}$ progeny were screened for $25 \%$ arrested $\mathrm{F}_{3}$ embryos. Candidates were then scored via Nomarski microscopy for expression of later stage differentiation markers such as pharynx development and pumping.

To isolate suppressors of ca201-associated embryonic lethality, let-502(ca201) dpy-5/unc-11 unc-40 animals were mutagenized with $25 \mathrm{~mm}$ EMS (Brenner 1974) and $3400 \mathrm{~F}_{1}$ were plated. Suppressor mutations were identified by the presence of visibly Dpy $\mathrm{F}_{2}$ animals. Three independent suppressors $(\mathrm{s} b 54$, $s b 55$, and $s b 56 \mid$ resulted in sterile Dpy adult animals and the mutations were recovered among their morphologically wildtype sibs. Hatching rates were determined as described in Mains et al. (1990).

sb54 maps in cis less than 0.05 map units from ca201, indicating that it likely is an intragenic event, as was confirmed by sequencing. $s b 55$ and $s b 56$ both map to the overlap of $m n D f 16$, $m n D f 61$, and $m n D f 68$ in the let-23 unc- 4 interval of chromosome II (data submitted to the Caenorhabditis Genetics Center).

\section{Transformation of C. elegans}

Transformation was performed by gonadal microinjection of DNA (Mello et al. 1991). For transformation rescue experiments, constructs containing let-502 $(20 \mu \mathrm{g} / \mathrm{ml})$ were coinjected with plasmid pRF4 containing the dominant rol-6/su1006) marker gene $(100 \mu \mathrm{g} / \mathrm{ml})$ into a phenotypically wild-type let502(ca201) dpy-5/unc-11 unc-40 strain. unc-11 and unc-40 flank let-502 and allow undesired recombinants to be detected. Rescue was evident by the presence of Rol Dpy $F_{1}$ progeny. The following cosmids were tested: C41D11, C44E4, B0308, ZK1017, B0041, T04D1, W09C3, C10H11, K06G1, M04F3, C17D9, F07H8, C01F4, and C04E4. A 14-kbp ClaI fragment from K06G1 efficiently rescued let-502(ca201) as did a 7.1-kbp EcoRV-XhoI subclone. Weak rescue /occasional hatched $\mathrm{L}_{1}$ larvae) could be obtained with the 5.5-kbp EcoRV-SphI fragment.

For transformation experiments with lacZ reporter constructs (Fire et al. 1990), let-502::1acZ fusions $(20 \mu \mathrm{g} / \mathrm{ml}$ ) were coinjected with pRF4 $(100 \mu \mathrm{g} / \mathrm{ml})$ into the $\mathrm{N} 2$ wild-type strain. Lines that stably transmitted the extrachromosomal arrays were established and embryos analyzed for $\beta$-galactosidase expression. To exclude the possibility that marker gene expression (rol-6) was driving hypodermal expression of the let-502::1ac Z fusion, transgenic lines were also established that contained the let-502::1acZ reporter together with the muscle specific transformation marker plasmid pPD10.41 (Fire et al. 1991). Embryos from these lines showed the same hypodermal lacZ expression pattern as did those where pRF4 had been used (data not shown).

The internal kinase deletion construct (shown in Fig. 2D; 50 $\mathrm{\mu g} / \mathrm{ml}$ ) was injected into $\mathrm{N} 2$ animals [using both a 1et-502::1acZ fusion $(50 \mu \mathrm{g} / \mathrm{ml})$ and pRF4 $(100 \mu \mathrm{g} / \mathrm{ml})$ as transformation markers] and $F_{1}$ progeny phenotypes were scored. Arrested ca201-like embryos stained for $\beta$-galactosidase activity $(5 / 5)$, thereby confirming the presence of transforming DNA. For transformation rescue experiments with mel-11, constructs $(40-100 \mu \mathrm{g} / \mathrm{ml})$ were coinjected with pRF4 $(100 \mu \mathrm{g} / \mathrm{ml})$ into a phenotypically wild-type unc-4(e120) sb56/mnC1 strain. Lines with stably transmitting arrays were established and fertile Rol Unc-4 segregants indicated rescue.

\section{Transformation constructs}

A let-502::lacZ fusion containing a nuclear localization signal was made by cloning the $6.6-\mathrm{kbp} \mathrm{ClaI}-\mathrm{BamHI}$ fragment into the single BamHI site of pPD21.28 (Fire et al. 1990). The non- nuclear localized let-502::1acZ construct was made by cloning the $4.2-\mathrm{kbp}$ HindIII fragment into the single HindIII site of pPD21.28 and then removing the nuclear localization signal by $K p n I$ digestion and religation.

To create the internal deletion within the kinase domain of LET-502 (Fig. 2D), a 1030-bp BamHI fragment was excised from the 14-kbp genomic ClaI fragment (Fig. 2B) and the remaining fragments were religated. This leads to an in-frame deletion of amino acid residues 14 to 138 , thereby removing the ATP-binding domain within the kinase domain (Taylor et al. 1992).

\section{Antibody techniques}

Embryos were isolated with alkaline hypochloride, bleach permeabilized, fixed, and stained (Barstead and Waterston 1991). Dilutions used for the primary antibodies were: anti- $\beta$-galactosidase antibody (Promega) 1:1000, MH27 (Francis and Waterston 1991) 1:1000, and DM5.6 (Miller et al. 1983) 1:100. The secondary antibody was a rhodamine-conjugated goat antimouse antibody (Jackson Immunoresearch Laboratories).

\section{Cloning of let-502 cDNA}

To obtain the let-502 cDNA, the genomic 7.1-kbp EcoRV-XhoI rescuing fragment was used to screen $\sim 200,000$ plaques of a $C$. elegans mixed-stage library (Barstead and Waterston 1989). Eleven positive clones were identified: The two largest clones were identical ( $4275 \mathrm{bp}$ ) and the nine remaining smaller cDNAs were contained within the longest cDNA. The fusion between genomic let-502 DNA and let-502 cDNA was made by joining the 3.5-kbp EcoRV-HindIII genomic fragment and the 4164-bp $H$ indIII-ECoRI cDNA.

\section{Sequence determinations and computer analysis}

let-502 cDNA and genomic DNA were cloned in $\mathrm{pBS} \mathrm{SK}^{+}$and $5^{\prime}$ deletion series were generated using the Promega Erase-a-base kit. Plasmids were sequenced with the Applied Biosystems Taq DyeDeoxy Terminator Cycle Sequencing kit. Occasional gaps not covered by deletions were filled in by sequence-specific primers. All sequences were verified on both strands except for some small regions within the 5 '-untranscribed genomic region of let-502, where sequence for only one strand was obtained. Genomic Southerns using a series of five restriction enzymes confirmed the gene structure (data not shown). Sequence assembly, analysis, and alignment was done with the Wisconsin Genetics Computer Group Inc. DNA analysis package (Devereux et al. 1984). Coiled-coil predictions were done using the COILS2 program (Lupas 1996). The sequence alteration in mel11(sb55) was identified by sequencing PCR-amplified cDNA obtained from a homozygous mutant strain. The mutation changes an arginine codon (CGA) to a stop codon (TGA) at residue 772 of the protein and was subsequently verified by sequencing genomic DNA from this mutant strain.

\section{Northern analysis of let-502 expression}

One microgram of mixed stage $\mathrm{N} 2$ poly $(\mathrm{A})^{+}$mRNA (isolated with the Micro-Fast Track mRNA isolation kit, Invitrogen/ was run on a $1.2 \%$ formaldehyde agarose gel, blotted, and probed with a let-502 cDNA fragment containing the $5^{\prime}$ end of let-502 up to the internal XhoI site (see Fig. 2C). Even after prolonged exposure, only the single $4.3-\mathrm{kb}$ band was detected. 


\section{Single worm PCR of genomic DNA}

Single worm PCR of homozygous mutant C. elegans was done as described (Williams et al. 1992) except for omission of the initial freezing step. All mutations were verified by using independent PCR products obtained with different primer sets.

\section{Acknowledgments}

We thank A. Rose and D. Baillie for generously providing five alleles of let-502 as well as mapping strains, B. Williams for antibodies and excellent advice, R. Barstead for the cDNA library, A. Coulson and J. Sulston for cosmids, F. Allen, M. Chung, and B. Goszczynski for technical assistance, R. Dow for help with computer programs, and $\mathrm{M}$. Walsh for helpful discussions. Some $C$. elegans strains were obtained from the Caenorhabditis Genetics Center, funded by the National Institutes of Health Center for Research Resources. This work was supported in part by the Deutsche Forschungsgemeinschaft (A.W.), the Alberta Heritage Foundation for Medical Research (A.W., J.D.M., and P.E.M.), the Medical Research Council of Canada (J.D.M. and P.E.M.), the Ruth Rannie Memorial Endowment (J.D.M. and P.E.M.), the Howard Hughes Medical Institute (J.D.M.), and the Muscular Dystrophy Association of Canada (P.E.M. and J.D.M.).

The publication costs of this article were defrayed in part by payment of page charges. This article must therefore be hereby marked "advertisement" in accordance with 18 USC section 1734 solely to indicate this fact.

\section{Note added in proof}

The sequences reported in this paper (let-502, mel-11) have been deposited in the GenBank database (accession nos. U85515 and U86640, respectively).

\section{References}

Ahmed, S., R. Kozma, J. Lee, C. Monfries, N. Harden, and L. Lim. 1991. The cysteine-rich domain of human proteins, neuronal chimaerin, protein kinase $\mathrm{C}$ and diacylglycerol kinase binds zinc. Biochem. I. 280: 233-241.

Allen, B.G. and M.P. Walsh. 1994. The biochemical basis of the regulation of smooth muscle contraction. Trends Biochem. Sci. 19: 362-368.

Amano, M., M. Ito, K. Kimura, Y. Fukata, K. Chihara, T. Nakano, Y. Matsuura, and K. Kaibuchi. 1996. Phosphorylation and activation of myosin by Rho-associated kinase (Rho-kinase). J. Biol. Chem. 271: 20246-20249.

Anderson, P. 1995. Mutagenesis. In Caenorhabditis elegansModern biological analysis of an organism (ed. H.F. Epstein and D.C. Shakes), pp. 31-58. Academic Press, San Diego, CA.

Aroian, R.V., A.D. Levy, M. Koga, Y. Ohshima, J.M. Kramer, and P.W. Sternberg. 1993. Splicing in Caenorhabditis elegans does not require an AG at the $3^{\prime}$ splice acceptor site. Mol. Cell. Biol. 13: 626-637.

Barstead, R.J. and R.H. Waterston. 1989. The basal component of the nematode dense-body is vinculin. I. Biol. Chem. 264: $10177-10185$.

-1991. Vinculin is essential for muscle function in the nematode. J. Cell Biol. 114: 715-724.

Bikle, D.D., S. Munson, N. Morrison, and J. Eisman. 1993. Zipper protein, a newly des-cribed tropomyosin-like protein of the intestinal brush border. J. Biol. Chem. 268: 620-626.
Brenner, S. 1974. The genetics of Caenorhabditis elegans. Genetics 77: 71-94.

Brook, J.D., M.E. McCurrach, H.G. Harley, A.J. Buckler, D. Church, H. Aburatani, K. Hunter, V.P. Stanton, J.-P. Thirion, T. Hudson, R. Sohn, B. Zemelman, R.G. Snell, S.A. Rundle, S. Crow, J. Davies, P. Shelbourne, J. Buxton, C. Jones, V. Juvonen, K. Johnson, P.S. Harper, D.J. Shaw, and D.E. Housman. 1992. Molecular basis of myotonic dystrophy: Expansion of a trinucleotide (CTG) repeat at the $3^{\prime}$ end of a transcript encoding a protein kinase family member. Cell 68: 799-808.

Chant, J. and L. Stowers. 1995. GTPase cascades choreographing cellular behavior: Movement, morphogenesis and more. Cell 81: $1-4$.

Chen, W. and L. Lim. 1994. The Caenorhabditis elegans small GTP-binding protein RhoA is enriched in the nerve ring and sensory neurons during larval development. J. Biol. Chem. 269: 32394-32404.

Chen, W., H.H. Lim, and L. Lim. 1993a. A new member of the ras superfamily, the rac1 homologue from Caenorhabditis elegans. J. Biol. Chem. 268: 320-324.

- 1993b. The CDC42 homologue from Caenorhabditis elegans. I. Biol. Chem. 268: 13280-13285.

Chen, Y.H., M.X. Chen, D.R. Alessi, D.G. Campbell, C. Shanahan, P. Cohen, and P.T.W. Cohen. 1994. Molecular cloning of cDNA encoding the $110 \mathrm{kDa}$ and $21 \mathrm{kDa}$ regulatory subunits of smooth muscle protein phosphatase 1M. FEBS Lett. 356: 51-55.

Devereux, J., P. Haeberli, and O. Smithies. 1984. A comprehensive set of sequence analysis programs for the VAX. Nucleic Acids Res. 12: 387-395.

Erdödi, F., M. Ito, and D.J. Hartshorne. 1996. Myosin light chain phosphatase. In Biochemistry of smooth muscle contraction (ed. M. Bárány), pp. 131-142. Academic Press, San Diego, CA.

Fire, A., S.W. Harrison, and D. Dixon. 1990. A modular set of lacZ fusion vectors for studying gene expression in Caenorhabditis elegans. Gene 93: 189-198.

Fire, A., D. Albertson, S.W. Harrison, and D.G. Moerman. 1991. Production of antisense RNA leads to effective and specific inhibition of gene expression in C. elegans muscle. Development 113: 503-514.

Francis, R. and R.H. Waterston. 1991. Muscle cell attachment in Caenorhabditis elegans. J. Cell Biol. 114: 465-479.

Fristrom, D. 1988. The cellular basis of epithelial morphogenesis. A review. Tissue \& Cell 20: 645-690.

Fu, Y.-H., A. Pizzuti, R.G. Fenwick, J. King, S. Rajnarayan, P.W. Dunne, J. Dubel, G.A. Nasser, T. Ashizawa, P. De Jong, B. Wieringa, R. Korneluk, M.B. Perryman, H.F. Epstein, and C.T. Caskey. 1992. An unstable triplet repeat in a gene related to myotonic muscular dystrophy. Science 255: 12561258.

Fujiwara, T., T. Itoh, Y. Kubota, and H. Kuriyama. 1989. Effects of guanosine nucleotides on skinned smooth muscle tissue of the rabbit mesenteric artery. I. Physiol. 408: 535-547.

Gong, M.C., K. Iizuka, G. Nixon, J.P. Browne, A. Hall, J.F. Eccleston, M. Sugai, S. Kobayashi, A.V. Somlyo, and A.P. Somlyo. 1996. Role of guanine nucleotide-binding proteins-ras-family or trimeric proteins or both-in $\mathrm{Ca}^{2+}$ sensitization of smooth muscle. Proc. Natl. Acad. Sci. 93: 13401345.

Hall, A. 1994. Small GTP-binding proteins and the regulation of the actin cytoskeleton. Annu. Rev. Cell Biol. 10: 31-54.

Hanks, S.K. and T. Hunter. 1995. The eukaryotic protein kinase superfamily: Kinase (catalytic) domain structure and classification. FASEB J. 9: 576-596. 
Harper, P.S. 1989. Myotonic dystrophy. Saunders, Philadelphia, PA.

Howell, A.M. and A.M. Rose. 1990. Essential genes in the $h D f 6$ region of chromosome I in Caenorhabditis elegans. Genetics 126: $583-592$.

Hu, J.C., E.K. O'Shea, P.S. Kim, and R.T. Sauer. 1990. Sequence requirements for coiled-coils: Analysis with $\lambda$ repressorGCN4 leucine zipper fusions. Science 250: 1400-1403.

Ichikawa, K., M. Ito, and D.J. Hartshorne. 1996. Phosphorylation of the large subunit of myosin phosphatase and inhibition of phosphatase activity. J. Biol. Chem. 271: 4733-4740.

Ishizaki, T., M. Maekawa, K. Fujisawa, K. Okawa, A. Iwamatsu, A. Fujita, N. Watanabe, Y. Saito, A. Kakizuka, N. Morii, and S. Narumiya. 1996. The small GTP-binding protein Rho binds to and activates a $160 \mathrm{kDa}$ ser/thr protein kinase homologous to myotonic dystrophy kinase. EMBO J. 15: 18851893.

Jansen, G., P.J.T.A. Groenen, D. Bächner, P.H.K. Jap, M. Coerwinkel, F. Oerlemans, W. van den Broek, B. Gohlsch, D. Pette, J.J. Plomp, P.C. Molenaar, M.G.J. Nederhoff, C.J.A. van Echteld, M. Dekker, A. Berns, H. Hameister, and B. Wieringa. 1996. Abnormal myotonic dystrophy protein kinase levels produce only mild myopathy in mice. Nature Genet. 13: $316-324$.

Justice, R.W., O. Zilian, D.F. Woods, M. Noll, and P.J. Bryant. 1995. The Drosophila tumor suppressor gene warts encodes a homolog of human myotonic dystrophy kinase and is required for the control of cell shape and proliferation. Genes \& Dev. 9: 534-546.

Kemphues, K.J., M. Kusch, and N. Wolf. 1988. Maternal-effect lethal mutations on linkage group II of Caenorhabditis eIegans. Genetics 120: $977-986$.

Kennelly, P.J. and E.G. Krebs. 1991. Consensus sequences as substrate specificity determinants for protein kinases and protein phosphatases. J. Biol. Chem. 266: 15555-15558.

Kimura, K., M. Ito, M. Amano, K. Chihara, Y. Fukata, M. Nakafuku, B. Yamamori, J. Feng, T. Nakano, K. Okawa, A. Iwamatsu, and K. Kaibuchi. 1996. Regulation of myosin phosphatase by Rho and Rho-associated kinase (Rho-kinase). Science 273: 245-248.

Kitazawa, T., S. Kobayashi, K. Horiuti, A.V. Somlyo, and A.P. Somlyo. 1989. Receptor-coupled, permeabilized smooth muscle. J. Biol. Chem. 264: 5339-5342.

Kitazawa, T., M. Masuo, and A.P. Somlyo. 1991. G proteinmediated inhibition of myosin light-chain phosphatase in vascular smooth muscle. Proc. Nat1. Acad. Sci. 88: 93079310.

Krause, M. 1995. Transcription and translation. In Caenorhabditis elegans-Modern biological analysis of an organism (ed. H.F. Epstein and D.C. Shakes), pp. 483-512. Academic Press, San Diego, CA.

Krause, M. and D. Hirsh. 1987. A trans-spliced leader sequence on actin mRNA in Caenorhabditis elegans. Cell 49: 753761.

Kubota, Y., M. Nomura, K.E. Kamm, M.C. Mumby, and J.T. Stull. 1992. GTP $\gamma$ S-dependent regulation of smooth muscle contractile elements. Am. J. Physiol. 262: C405-C410.

Leung, T., E. Manser, L. Tan, and L. Lim. 1995. A novel serine/ threonine kinase binding the ras-related RhoA GTPase which translocates the kinase to the peripheral membranes. I. Biol. Chem. 270: 29051-29054.

Lupas, A. 1996. Prediction and analysis of coiled coils structures. Meth. Enzymol. 266: 513-525.

Mahadevan, M., C. Tsilfidis, L. Sabourin, G. Shutler, C. Amemiya, G. Jansen, C. Neville, M. Narang, J. Barceló, K. O'Hoy, S. Leblond, J. Earle-Macdonald, P.J. De Jong, B. Wieringa, and
R.G. Korneluk. 1992. Myotonic dystrophy mutation: An unstable CTG repeat in the $3^{\prime}$ untranslated region of the gene. Science 255: 1253-1255.

Mains, P.E., I.A. Sulston, and W.B. Wood. 1990. Dominant maternal-effect lethal mutations causing embryonic lethality in Caenorhabditis elegans. Genetics 125: 351-369.

Manstein, D.J., M.A. Titus, A. De Lozanne, and J.A. Spudich. 1989. Gene replacement in Dictyostelium: Generation of null mutants. EMBO J. 8: 923-932.

Matsui, T., M. Amano, T. Yamamoto, K. Chihara, M. Nakafuku, M. Ito, T. Nakano, K. Okawa, A. Iwamatsu, and K. Kaibuchi. 1996. Rho-associated kinase, a novel serine/threonine kinase, as a putative target for the small GTP binding protein Rho. EMBO T. 15: 2208-2216.

Mello, C.C., J.M. Kramer, D. Stinchcomb and V. Ambros. 1991. Efficient gene transfer in C. elegans: Extrachromosomal maintenance and integration of transforming sequences. EMBO I. 10: 3959-3970.

Miller, D.M., I. Ortiz, G.C. Berliner, and H.F. Epstein. 1983. Differential localization of two myosins within nematode thick filaments. Cell 34: 477-490.

Millward, T., P. Cron, and B.A. Hemmings. 1995. Molecular cloning and characterization of a conserved nuclear serine/threoninel protein kinase. Proc. Nat1. Acad. Sci. 92: 5022-5026.

Noda, M., C. Yasuda-Fukazawa, K. Moriishi, T. Kato, T. Okuda, K. Kurokawa, and Y. Takuwa. 1995. Involvement of tho in GTP $\gamma$ S-induced enhancement of phosphorylation of $20 \mathrm{kDa}$ myosin light chain in vascular smooth muscle cells: Inhibition of phosphatase activity. FEBS Lett. 367: 246-250.

Otto, E., M. Kunimoto, T. McLaughlin, and V. Bennett. 1991. Isolation and characterization of cDNAs encoding human brain ankyrins reveal a family of alternatively spliced genes. I. Cell Biol. 114: 241-253.

Parker, P.J., L. Coussens, N. Totty, L. Rhee, S. Young, E. Chen, S. Stabel, M.D. Waterfield, and A. Ullrich. 1986. The complete primary structure of protein kinase C-The major phorbol ester receptor. Science 233: 853-859.

Priess, J.R. and D.I. Hirsh. 1986. Caenorhabditis elegans morphogenesis: The role of the cytoskeleton in elongation of the embryo. Dev. Biol. 117: 156-173.

Reddy, S., D.B.J. Smith, M.M. Rich, J.M. Leferovich, P. Reilly, B.M. Davis, K. Tran, H. Rayburn, R. Bronson, D. Cros, R.J. Balice-Gordon, and D. Housman. 1996. Mice lacking the myotonic dystrophy protein kinase develop a late onset progressive myopathy. Nature Genet. 13: 325-335.

Sellers, J.R. 1991. Regulation of cytoplasmic and smooth muscle myosin. Curr. Opin. Cell Biol. 3: 98-104.

Shimizu, H., M. Ito, M. Miyahara, K. Ichikawa, S. Okubo, T. Konishi, M. Naka, T. Tanaka, K. Hirano, D.J. Hartshorne, and T. Nakano. 1994. Characterization of the myosin-binding subunit of smooth muscle myosin phosphatase. $/$. Biol. Chem. 269: 30407-30411.

Shoji, S., L.H. Ericsson, K.A. Walsh, E.H. Fisher, and K. Titani. 1983. Amino acid sequence of the catalytic subunit of bovine type II adenosine cyclic $3^{\prime}, 5^{\prime}$-phosphate dependent protein kinase. Biochemistry 22: 3702-3709.

Singh, R.N. and J.E. Sulston. 1978. Some observations on moulting in Caenorhabditis elegans. Nematologica 24: 63-71.

Somlyo, A.P. and A.V. Somlyo. 1994. Signal transduction and regulation in smooth muscle. Nature 372: 231-236.

Springer, M.L., B. Patterson, and J.A. Spudich. 1994. Stage-specific requirement for myosin II during Dictyostelium development. Development 120: 2651-2660.

Sulston, J.E., E. Schierenberg, J.G. White, and J.N. Thomson. 
Wissman et al.

1983. The embryonic cell lineage of the nematode Caenorhabditis elegans. Dev. Biol. 100: 64-119.

Tan, J.L., S. Ravid, and J.A. Spudich. 1992. Control of nonmuscle myosins by phosphorylation. Annu. Rev. Biochem. 61: 721-759.

Taylor, S.S., D.R. Knighton, J. Zheng, L.F. Ten Eyck, and J.M. Sowadski. 1992. Structural framework for the protein kinase family. Annu. Rev. Cell Biol. 8: 429-462.

von Kalm, L., D. Fristrom, and J. Fristrom. 1995. The making of a fly leg: A model for epithelial morphogenesis. BioEssays 17: 693-702.

Waterston, R. and J. Sulston. 1995. The genome of Caenorhabditis elegans. Proc. Nat1. Acad. Sci. 92: 10836-10840.

Williams, B.D., B. Schrank, C. Huynh, R. Shownkeen, and R.H. Waterston. 1992. A genetic mapping system in Caenorhabditis elegans based on polymorphic sequence-tagged sites. Genetics 131: 609-624.

Yarden, O., M. Plamann, D.J. Ebbole, and C. Yanofsky. 1992. $\cot -1$, a gene required for hyphal elongation in Neurospora crassa, encodes a protein kinase. EMBO J. 11: 2159-2166.

Young, P.E., A.M. Richman, A.S. Ketchum, and D.P. Kiehart. 1993. Morphogenesis in Drosophila requires nonmuscle myosin heavy chain function. Genes \& Dev. 7: 29-41. 


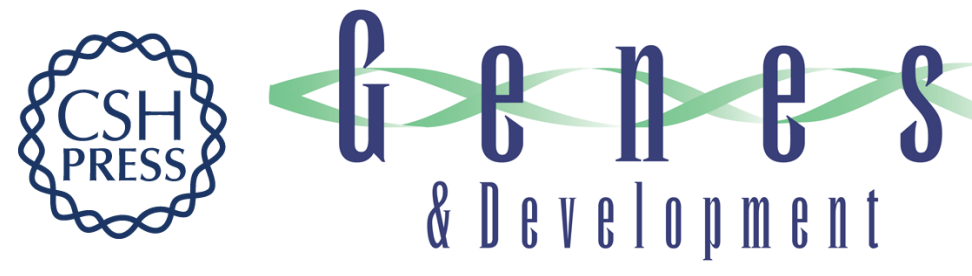

\section{Caenorhabditis elegans LET-502 is related to Rho-binding kinases and human myotonic dystrophy kinase and interacts genetically with a homolog of the regulatory subunit of smooth muscle myosin phosphatase to affect cell shape.}

A Wissmann, J Ingles, J D McGhee, et al.

Genes Dev. 1997, 11:

Access the most recent version at doi:10.1101/gad.11.4.409

References This article cites 65 articles, 34 of which can be accessed free at: http://genesdev.cshlp.org/content/11/4/409.full.html\#ref-list-1

License

Email Alerting

Receive free email alerts when new articles cite this article - sign up in the box at the top Service right corner of the article or click here.

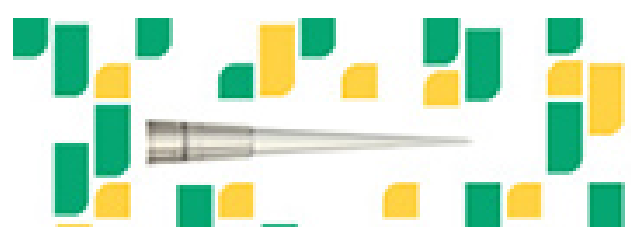

Focused on your science. 